Vol 41 (2016) No 184 59-73

\title{
Antecedents of Work-Family Conflict within Higher Education Setting
}

\author{
Ayşe Negiş Işık ${ }^{1}$, Erkan Işık ${ }^{2}$, Erdal Hamarta ${ }^{3}$
}

\begin{abstract}
This study examined the potential antecedents of multidimensional work-family conflict in a sample of 828 academic staff. Following previous meta-analyses, antecedents of work-family conflict were categorized into three domains as individual/demographic (e.g., gender), work (e.g., work role overload), and nonwork/family (e.g., family role overload) variables. Multidimensional Work Family Conflict Scale (MWFCS) was used to measure each three types (time-based, strain-based, and behavior-based) of work-family and familywork conflict. After controlling for individual and family domain variables, work domain variables added significant variance in predicting all types of work-family conflict. Similarly, after controlling for individual and work domain variables, family domain variables added significant variance in predicting familywork conflict variables, except for behavior-based family-work conflict. Implications of these findings for practice and future research on work-family conflict were discussed.
\end{abstract}

Keywords

\begin{tabular}{r} 
Keywords \\
\hline Work family conflict \\
Ffamily work conflict \\
Antecedents \\
Higher education \\
Academic staff \\
Article Info \\
Received: 09.12 .2015 \\
Accepted: 26.02 .2016 \\
Online Published: 27.04 .2016
\end{tabular}

\section{Introduction}

Work-family conflict is one of the most studied concepts in the work-family literature (Byron, 2005), mostly due to the increasing number of dual-earner families and overloaded work/family responsibilities. This increase makes the conflict between work and family life virtually inevitable because both domains of life has its own competing demands. Work family conflict, also called work family interface, is defined as the discrepancy that occurs when the time devoted to work role or the strain created by the work role interferes with fulfilling family responsibilities or vice versa (Netemeyer, Boles, \& McMurrian, 1996). Work family conflict is considered a multidimensional construct which has two directions and three forms of conflict (Carlson, Kacmar, \& Williams, 2000). Two directions are work to family conflict (WFC) and family to work conflict (FWC). These two directions of conflict is considered reciprocal that one direction can interfere with the other and both directions must be considered for a better understanding of the construct (Frone, Russell, \& Cooper, 1992). Three forms of conflict are time-based conflict, strain-based conflict, and behavior-based conflict (Greenhaus \& Beutell, 1985): Time-based conflict occurs when time devoted to activities in one role interferes with fulfilling responsibilities of another role; strain-based conflict occurs when strain

\footnotetext{
${ }^{1}$ Mevlana University, Education Faculty, Department of Educational Administration, Turkey, anegis@mevlana.edu.tr

${ }^{2}$ Mevlana University, Education Faculty, Department of Guidance and Psychological Counseling, Turkey,

eisik@mevlana.edu.tr

${ }^{3}$ Necmettin Erbakan University, Ahmet Keleşoğlu Education Faculty, Department of Guidance and Psychological Counseling,

Turkey, ehamarta@konya.edu.tr
} 
created by one role such as anxiety or fatigue interferes with fulfilling responsibilities of another role; and behavior-based conflict occurs when specific behaviors or values expected in one role such as competition or power are incompatible with behaviors or values expected in another role.

Previous research has demonstrated that work family conflict may lead to both personal and organizational problems such as depression (Allen, Herst, Bruck, \& Sutton, 2000; Britt \& Dawson, 2005; Frone, 2000; Hammer, Cullen, Neal, Sinclair, \& Shafiro, 2005; Symoens \& Bracke, 2015), parental distress (Kinnunen, Feldt, Mauno, \& Rantanen, 2010), hypertension (Allen et al., 2000), absenteeism (Greenhaus, Parasuraman, \& Collins, 2001), exhaustion (Nohe \& Sonntag, 2014; Rantanen, Kinnunen, Feldt, \& Pulkkinen, 2008), and burnout (Amstad, Meier, Fasel, Elfering, \& Semmer, 2011; Reichl, Leiter \& Spinath, 2014). Although many potential harmful effects of work-family conflict on individual and organizational basis are well documented, variables that cause work-family conflict needs further exploration.

Besides, whereas work family conflict studies have been conducted on varied professions such as nurses (Burke \& Greenglass, 2001; Cohen \& Kirchmeyer, 1995; Fox \& Dwyer, 1999), school teachers (Kirchmeyer \& Cohen, 1999), lawyers (Cinamon \& Rich, 2002), probation and parole officers (Boles, Howard, \& Donofrio, 2001), hotel managers (Perrewe, Hochwarter, \& Kiewtiz, 1999), and civil servants (Stoeva, Chiu, \& Greenhaus, 2002), there needs to be a clearer understanding of the antecedents of work family conflict in higher education settings where work overload, unscheduled work load, long working hours, diversity of teaching and research roles are in common. Cross-sectoral studies comparing work-family conflict between people working in higher education and other sectors consistently reported that university employees experience greater work/family imbalance and they are more negative about balancing work family issues and their workplace's work family climate (Anderson, Coffey, \& Byerly, 2002; Anderson, Morgan, \& Wilson, 2002; Pillay, Kluvers, Abhayawansa, \& Vranic, 2013). According to a study conducted by Currie, Harris, and Thiele (2000), both men and women academic staff believed that they work above and beyond the call of duty, thereby sacrificing their families, friends, and their health. Another problematic issue about working as an academician is the idea of "publish or perish" which adds much more strain on the workloads of academic staff (Pillay \& Abhayawansa, 2014).

Following previous meta-analytic research (Byron, 2005; Michel, Kotrba, Mitchelson, Clark, \& Baltes, 2011), antecedents of work-family conflict can be categorized into three distinct domains as individual/demographic variables, work variables, and nonwork/family variables. Individual/demographic domain variables are about the personal characteristics such as gender, age, income, locus of control, personality type, affectivity, coping style and skills. Work domain variables focus on work-related factors such as job involvement, job stress, work role overload, work role ambiguity, work support, schedule flexibility, and task variety. Nonwork/family domain variables focus on factors related mostly to family demands such as family involvement, family stress, family role overload, family role ambiguity, family support, number of children, age of the youngest child, and spousal employment. The current study examines five individual/demographic domain antecedents (gender, age, title, tenure, income); three work domain antecedents (work role overload, work role ambiguity, schedule control); and five nonwork/family domain antecedents (family role overload, family role ambiguity, marital status, spousal employment, number of children, age of the youngest child).

These antecedents were selected from each domain because of their reported relationships to work family conflict, as well as their theoretical backgrounds. For instance, work role overload and role ambiguity were consistently associated with higher levels of work family conflict whereas those with more flexible job schedules reported less work family conflict (Byron, 2005). Individuals who are married and/or have children are often expected to have more family responsibilities and family work conflict as well (Michel et al., 2011). Age of the youngest child is also an important factor since individuals with younger children are likely to report higher levels of work family conflict when compared with parents of older children (Darcy \& McCarthy, 2007; Staines \& O'Connor, 1980). Two emerging theories explaining potential linkages between work family conflict and its antecedents are 
role theory and resource drain theory. According to role theory (Kahn, Wolfe, Quinn, Snoek, \& Rosenthal, 1964), each role an individual inhabits such as wife, husband, employer, employee, parent, or child brings its own responsibilities, demands, and expectations, which causes a pressure. The simultaneous occurrence of these pressures make compliance among these roles much more difficult (Kahn et al., 1964). Similarly, the resource drain theory argues that people transfer their personal resources such as time, attention, and energy from one role to the other but all these resources are limited (Edwards \& Rothbard, 2000). Thus, conflict between roles occurs since using these limited resources for one role will reduce the available resources to use for the other role (Morris \& Madsen, 2007).

Another issue about the potential associations between these antecedents and work family conflict is its bidirectional nature. As noted, work-related factors may interfere with family responsibilities as well as family-related factors may interfere with work responsibilities. Thus, each antecedents within different domains may have different effects on WFC and FWC at which work domain variables are expected to be more associated to WFC than to FWC (Byron, 2005). Taken together, more attention is needed regarding potential antecedents of multidimensional work family conflict among academic staff. Drawing on the above theorizing and empirical findings, following hypotheses were generated:

Hypothesis 1: After controlling for individual and family domain variables, work domain variables will explain a significant variance in three forms of WFC (i.e., time-based, strain-based, and behavior-based).

Hypothesis 2: After controlling for individual and work domain variables, family domain variables will explain a significant variance in three forms of FWC (i.e., time-based, strain-based, and behavior-based).

\section{Method}

\section{Participants}

The participants consisted of 828 academic staff between the ages of 23 and 67, with a mean age of 35.6 years $(S D=8.1)$. Of the participants $443(53.5 \%)$ were male and $385(46.5 \%)$ were female. Around $6 \%$ held the rank of professor, $11 \%$ were associate professors, $30 \%$ were assistant professors, $19 \%$ were instructors, and $34 \%$ were research assistants. The mean number of years at the current university (tenure) was $6.6(S D=6.7)$. Most participants were married $(78 \%)$ and have at least one child (58\%).

\section{Procedure}

Of the 193 universities in Turkey, 87 public and private universities were randomly selected from all regions of Turkey. A total of 8216 academic staff were sent an e-mail with an introduction letter asking for participation in a work-family study and were provided with a link to on-line survey packets. A $10.1 \%$ response rate was achieved with 835 questionnaires returned.The questionnaires took approximately 10 minutes to complete and all data for this study were collected over a threeweek period. Since there were no Turkish forms of the instruments used in this study, all instruments were translated into Turkish through a backtranslation procedure. In the first step, the first and second author independently translated the measures from English to Turkish. Second, the translated versions were then back-translated independently by a graduate student who holds a bachelor's degree in English language and literature and another graduate student who received a master's degree in the United States. Then, the first and second author reviewed the back-translated versions of each item and compared with the original version for meaning accuracy. After a careful examination of English and Turkish versions of the measures, discrepancies were resolved and the meanings of several words were clarified and reworded. Findings about the psychometric properties of the translated instruments were given where the instruments were presented. 


\section{Instruments}

Demographic form. Participants completed items regarding their gender, age (in years), title (in rank order), marital status, spousal employment, number of children, and age of their youngest child.

Work family conflict. The Work-Family Conflict Scale (WFCS; Carlson et al., 2000) was used to measure participants' level of work family conflict. The WFCS is an 18-item multidimensional measure which assesses six dimensions of work family conflict. These six dimensions are a combination of three forms (Time, strain, and behavior-based) and two directions (Work to family; Family to work) of conflict. Ratings are made on a five-point scale from Strongly Disagree (1) to Strongly Agree (5). Sample items include: (a) Time-based WFC ("My work keeps me from my family activities more than I would like"); (b) Strain-based WFC ("When I get home from work I am often too frazzled to participate in family activities/responsibilities"); (c) Behavior-based WFC ("The problemsolving behaviors I use in my job are not effective in resolving problems at home"); (d) Time-based FWC ("The time I spend on family responsibilities often interfere with my work responsibilities"); (e) Strain-based FWC ("Due to stress at home, I am often preoccupied with family matters at work"); (f) Behavior-based FWC ("The behaviors that work for me at home do not seem to be effective at work"). Higher scores indicate higher levels of conflict experienced. The Cronbach alpha reliability coefficient ranged from .78 to .87 and convergent validity was supported with significant relationships with potential antecedents and outcome variables (Carlson et al., 2000). Psychometric properties of the Turkish version of WFCS were examined within the current study. Turkish version of WFCS had also good internal reliability values ranging from .81 to .92 . Confirmatory factor analysis with maximum likelihood (ML) estimation was conducted usingAMOS (16.0). As a combined rule for the acceptance of the model, five measures of fit indices were used with the following values: the chi-square/degrees of freedom (df) ratio $>3$, the goodness-of-fit-index (GFI), adjusted goodness-of-fit-index (AGFI), and the comperative-fit-index $(\mathrm{CFI})>.90$, and the root mean square error of approximation $(\mathrm{RMSEA})<.08$ (Browne \& Cudeck, 1993; Hu \& Bentler, 1999). The model indices were: $\chi^{2} / d f=2.32$, GFI $=.93, \mathrm{AGFI}=$ $.91, \mathrm{CFI}=.97, \mathrm{RMSEA}=.053$, suggesting an acceptable fit of the model to the data.

Role overload. Work role overload was assessed with three items from Thiagarajan, Chakrabarty, and Taylor's (2006) Role Overload Scale. These items were: "I have to do things that I do not really have the time and energy for." "I need more hours in the day to do all the things that are expected of me." "I cannot ever seem to catch up." Following Matthews, Kath, and Barnes-Farrell (2010), family role overload was measured with the same items but participants were asked to consider their family/home life when responding to the items. Ratings are made on a seven-point scale from Never (1) to Always (7). Higher scores indicate higher levels of role overload experienced. The Cronbach alpha for the current study was .91 for work role overload and .90 for family role overload, suggesting a high internal consistency.

Role ambiguity. Work role ambiguity was assessed with two items from Schuler, Aldag, and Brief's (1977) Role Conflict and Ambiguity Scale. These items were: "I know what my responsibilities are." and "I know exactly what is expected of me." Family role ambiguity was assessed with the same items asking participants to consider their family/home life when responding to the items. Ratings are made on a seven-point scale from Strongly Disagree (1) to Strongly Agree (7). Items were reverse coded so that higher scores indicated higher levels of role ambiguity experienced. The Cronbach alpha for the current study was .85 for work role ambiguity and .86 for family role ambiguity, suggesting a high internal consistency. 
Schedule control. Following Stewart (2013), schedule control was measured through a single item asking participants how much they feel like they have control over the setting of their work hours. Ratings are made on a five-point scale from None (1) to Complete (5) suggesting that higher scores indicated more control over one's schedule.

\section{Analyses}

Prior to analyses, all variables were examined for accuracy of data entry, outliers, and assumptions for normal distribution, linearity, and multicollinearity. Specifically, skewness and kurtosis values ranged from -.19 to .53 and -.53 to -.64 respectively and normal probability plots of the residuals and residual histograms confirmed normality. No problems were detected with multicollinearity as all correlations were well below .90 (Tabachnick \& Fidell, 2001). Durbin-Watson statistics ranged from 1.81 to 2.03 , which were close to 2, indicating support for the independence of errors (Tabachnick \& Fidell, 2001). Seven outliers detected based on Mahalanobis Distance score were deleted from the data set. Therefore, only 828 of the original 835 participants were included in further analyses. Total scores were used for study variables. Descriptive statistics, Pearson $r$ correlations and a series of hierarchical regression analysis were conducted to test the hypotheses. Independent variables included dichotomous variables. When calculating correlations between dichotomous and continuous variables, point biserial correlations should be calculated. Following Tabachnick and Fidell's (2001, p. 914) suggestions that "If the dichotomous variable is coded $0-1$, all the correlations can be calculated using the equation for Pearson product-moment correlation" dichotomous variables were dummy coded as $0-1$ and Pearson $r$ correlations were calculated. To test the relative contributions of work domain variables on work family conflict dimensions, individual variables were entered in the first block, family domain variables were entered in the second block, and work domain variables were entered in the third block. Similarly, to test the relative contributions of family domain variables on family work conflict dimensions, individual variables were entered in the first block, work domain variables were entered in the second block, and family domain variables were entered in the third block.

\section{Results}

Table 1 presents the basic descriptive statistics and correlations for the study variables. From the work family conflict variables, time-based WFC had the highest mean score $(M=8.16)$, followed by time-based FWC $(M=7.74)$, behavior-based WFC $(M=7.55)$, behavior-based FWC $(M=7.29)$, strainbased FWC $(M=7.22)$, and strain-based WFC $(M=7.21)$. Correlational analyses demonstrated that work role overload was positively related to each of the three forms of WFC ( $r=.29-.44)$ and work role ambiguity was positively related to only strain-based WFC $(r=-.12)$. Schedule control was negatively related to each of the three forms of WFC $(r=-.23--.31)$. Family role overload was positively related to each of the three forms of FWC $(r=.29-.44)$ whereas family role ambiguity, marital status, spousal employment, and the number of children were positively related to only one or two dimensions of FWC. The age of the youngest child was negatively related to each of the three forms of FWC $(r=-.23--.31)$. 
Table 1. Means, Standard Deviations, and Correlations among the Study Variables

\begin{tabular}{|c|c|c|c|c|c|c|c|c|c|c|c|c|c|c|c|c|c|c|}
\hline & 1 & 2 & 3 & 4 & 5 & 6 & 7 & 8 & 9 & 10 & 11 & 12 & 13 & 14 & 15 & 16 & 17 & 18 \\
\hline 1. Gender & - & & & & & & & & & & & & & & & & & \\
\hline 2. Age (in years) & $.18^{* * *}$ & - & & & & & & & & & & & & & & & & \\
\hline 3. Tenure (in years) & .04 & $.62^{* * *}$ & - & & & & & & & & & & & & & & & \\
\hline 4. Family role overload & $-.23^{* * *}$ & -.05 & -.03 & - & & & & & & & & & & & & & & \\
\hline 5. Family role ambiguity & .05 & $-.09^{*}$ & $-.07^{*}$ & $-.09^{*}$ & - & & & & & & & & & & & & & \\
\hline 6. Marital status & $.21^{* * *}$ & $.31^{* * *}$ & $.13^{* * *}$ & .03 & -.02 & - & & & & & & & & & & & & \\
\hline 7. Spousal employment & $-.42^{* * *}$ & $-.16^{* * *}$ & -.07 & $.19^{* * *}$ & .02 & $.12^{* *}$ & - & & & & & & & & & & & \\
\hline 8. Number of children & $.26^{* * *}$ & $.59^{* * * *}$ & $.37^{* * *}$ & .01 & -.04 & $.49^{* * * *}$ & $-.16^{* * *}$ & - & & & & & & & & & & \\
\hline 9. Age of young child & $.11^{*}$ & $.83^{* * *}$ & $.48^{* * *}$ & $-.16^{* *}$ & -.02 & $-.14^{* *}$ & $-.21^{* * *}$ & $.25^{* * *}$ & - & & & & & & & & & \\
\hline 10. Work role overload & $-.12^{* * *}$ & $-.07^{*}$ & -.02 & $.64^{* * *}$ & $-.11^{* *}$ & -.06 & $.14^{* *}$ & $-.08^{*}$ & $-.14^{* *}$ & - & & & & & & & & \\
\hline 11. Work role ambiguity & -.02 & $-.16^{* * *}$ & $-.14^{* * *}$ & -.04 & $.48^{* * *}$ & -.03 & -.01 & $-.12^{* * *}$ & -.07 & -.04 & - & & & & & & & \\
\hline 12. Schedule control & $.11^{* *}$ & $.18^{* * *}$ & $.11^{* *}$ & $-.25^{* * *}$ & -.03 & $.11^{* *}$ & -.09 & .15 & .09 & $-.28^{* * *}$ & $-.19^{* * * *}$ & - & & & & & & \\
\hline 13. Time-based WFC & .01 & $-.15^{* * *}$ & $-.11^{* *}$ & $.38^{* * *}$ & .01 & $-.08^{*}$ & .05 & $-.07^{*}$ & $-.15^{* *}$ & $.44^{* * *}$ & .04 & $-.31^{* * *}$ & - & & & & & \\
\hline 14. Strain-based WFC & $-.08^{* *}$ & $-.14^{* * *}$ & -.07 & $.36^{* * *}$ & $.07^{*}$ & $-.13^{* * *}$ & .02 & $-.11^{* *}$ & -.08 & $.41^{* * * *}$ & $.12^{* * *}$ & $-.31^{* * *}$ & $.62^{* * *}$ & - & & & & \\
\hline 15. Behavior-based WFC & .03 & $-.11^{* *}$ & -.07 & $.28^{* * *}$ & .04 & -.03 & .03 & -.01 & $-.18^{* * *}$ & $.29^{* * *}$ & .04 & $-.23^{* * *}$ & $.49^{* * *}$ & $.52^{* * *}$ & - & & & \\
\hline 16. Time-based FWC & $-.13^{* * *}$ & $-.12^{* * *}$ & -.07 & $.43^{* * *}$ & -.02 & .01 & $.15^{* * *}$ & .02 & $-.25^{* * *}$ & $.39^{* * *}$ & .01 & $-.22^{* * *}$ & $.51^{* * *}$ & $.45^{* * *}$ & $.48^{* * *}$ & - & & \\
\hline 17. Strain-based FWC & .01 & $-.19^{* * *}$ & $-.12^{* *}$ & $.29^{* * * *}$ & $.07^{*}$ & $-.09^{*}$ & .07 & $-.11^{* *}$ & $-.21^{* * *}$ & $.25^{* * *}$ & .04 & $-.23^{* * *}$ & $.41^{* * *}$ & $.44^{* * *}$ & $.64^{* * *}$ & $.54^{* * *}$ & - & \\
\hline 18. Behavior-based FWC & -.01 & $-.12^{* * *}$ & -.05 & $.26^{* * *}$ & .01 & $-.09^{* *}$ & .05 & -.06 & $-.12^{*}$ & $.27^{* * * *}$ & $.09^{*}$ & $-.26^{* * *}$ & $.43^{* * *}$ & $.51^{* * *}$ & $.73^{* * *}$ & $.43^{* * *}$ & $.52^{* * *}$ & - \\
\hline$M$ & 0.54 & 35.6 & 6.55 & 11.86 & 3.96 & 0.78 & 0.74 & 1.01 & 6.64 & 13.57 & 4.51 & 3.23 & 8.16 & 7.21 & 7.55 & 7.74 & 7.22 & 7.29 \\
\hline$S D$ & 0.51 & 8.11 & 6.67 & 4.93 & 2.63 & 0.42 & 0.44 & 1.07 & 6.31 & 4.93 & 2.98 & 1.13 & 3.16 & 3.12 & 3.09 & 3.08 & 3.27 & 3.21 \\
\hline
\end{tabular}

Note: Gender: 0-female, 1-male; Marital Status: 0-single, 1-married; Spousal employment: 0-does not work, 1-works

${ }^{*} \mathrm{p}<.05,{ }^{* *} \mathrm{p}<.01,{ }^{* * *} \mathrm{p}<.001$ 
Table 2. Summary of Hierarchical Regression Analysis for Variables Predicting Time-based WFC

\begin{tabular}{|c|c|c|c|c|c|c|c|c|c|}
\hline \multirow[b]{2}{*}{ Variable } & \multicolumn{3}{|c|}{ Model 1} & \multicolumn{3}{|c|}{ Model 2} & \multicolumn{3}{|c|}{ Model 3} \\
\hline & $B$ & $S E B$ & $\beta$ & $B$ & $S E B$ & $\beta$ & $B$ & $S E B$ & $\beta$ \\
\hline Gender & .66 & .31 & $.11^{*}$ & .75 & .33 & $27^{* *}$ & .29 & .32 & $.19^{* *}$ \\
\hline Age (in years) & -.05 & .02 & $-.13^{*}$ & -.02 & .04 & -.05 & -.02 & .03 & -.05 \\
\hline Tenure (in years) & -.01 & .02 & -.03 & -.01 & .02 & -.03 & -.02 & .02 & -.05 \\
\hline Family role overload & & & & .26 & .03 & $.42^{* *}$ & .08 & .04 & $.13^{*}$ \\
\hline Family role ambiguity & & & & -.01 & .05 & -.01 & .03 & .06 & .03 \\
\hline Marital status & & & & -.85 & .89 & -.02 & -.57 & .97 & -.01 \\
\hline Spousal employment & & & & .49 & .34 & .07 & .27 & .32 & .04 \\
\hline Number of children & & & & .01 & .20 & .01 & .13 & .19 & .03 \\
\hline Age of young child & & & & -.02 & .04 & -.04 & -.02 & .04 & -.04 \\
\hline Work role overload & & & & & & & .19 & .04 & $.32^{* *}$ \\
\hline Work role ambiguity & & & & & & & -.07 & .06 & -.06 \\
\hline Schedule control & & & & & & & -.65 & .13 & $-.23^{* *}$ \\
\hline$R^{2}$ & & .03 & & & & & & .30 & \\
\hline Adjusted $R^{2}$ & & .02 & & & & & & .28 & \\
\hline$F$ for change in $R^{2}$ & & $3.88^{*}$ & & & $14.72^{* *}$ & & & $20.18^{* *}$ & \\
\hline
\end{tabular}

Gender: 0-female, 1-male; Marital Status: 0-single, 1-married; Spousal employment: 0-unemployed, 1-employed; ${ }^{*} \mathrm{p}<.05,{ }^{* *} \mathrm{p}<.001$.

\section{Results of Regression Analyses for Time-based WFC}

The results of the regression analyses for time-based WFC are shown in Table 2. As seen, men reported more time-based WFC than women $(\beta=.11, p<.05)$. Family domain variables accounted for $16 \%$ of the variance in time-based WFC, with family role overload being the only significant predictor $(\beta=.42, p<.001)$. Finally, as predicted, work domain variables accounted for an additional $11 \%$ of variance in time-based WFC after controlling for the individual and family domain variables. In this final step, there were two significant work domain predictors, one individual domain factor, and one family domain factor; work role overload was the strongest predictor $(\beta=.32, p<.001)$ followed by schedule control $(\beta=-.23, p<.001)$, gender $(\beta=.19, p<.001)$, and family role overload $(\beta=.13, p<.05)$.

\section{Results of Regression Analyses for Strain-based WFC}

The results of the regression analyses for strain-based WFC are shown in Table 3. As seen, no individual factors were significant. Family domain variables accounted for $5 \%$ of the variance in strain-based WFC, with family role overload being the only significant predictor $(\beta=.32, p<.001)$. Finally, as predicted, work domain variables accounted for an additional $12 \%$ of variance in strainbased WFC after controlling for the individual and family domain variables. In this final step, there were only two significant work domain predictors; work role overload was the strongest predictor $(\beta=$ $.32, p<.001)$ followed by schedule control $(\beta=-.24, p<.001)$. 
Table 3. Summary of Hierarchical Regression Analysis for Variables Predicting Strain-based WFC

\begin{tabular}{|c|c|c|c|c|c|c|c|c|c|}
\hline \multirow[b]{2}{*}{ Variable } & \multicolumn{3}{|c|}{ Model 1} & \multicolumn{3}{|c|}{ Model 2} & \multicolumn{3}{|c|}{ Model 3} \\
\hline & $B$ & $S E B$ & $\beta$ & $B$ & $S E B$ & $\beta$ & $B$ & $S E B$ & $\beta$ \\
\hline Gender & -.21 & .29 & -.04 & .37 & .32 & .06 & -.02 & .31 & -.01 \\
\hline Age & -.02 & .02 & -.05 & -.01 & .04 & -.03 & -.01 & .04 & -.01 \\
\hline Tenure & .01 & .02 & .03 & .01 & .02 & .03 & .01 & .02 & .02 \\
\hline Family role overload & & & & .19 & .03 & $.32^{* *}$ & .01 & .04 & .02 \\
\hline Family role ambiguity & & & & .04 & .05 & .04 & .02 & .06 & .02 \\
\hline Marital status & & & & .62 & .84 & .04 & .77 & .92 & .04 \\
\hline Spousal employment & & & & -.02 & .33 & -.01 & -.24 & .31 & -.04 \\
\hline Number of children & & & & .23 & .19 & .07 & .35 & .19 & .09 \\
\hline Age of young child & & & & -.02 & .04 & -.03 & -.01 & .04 & -.03 \\
\hline Work role overload & & & & & & & .18 & .04 & $.32^{* *}$ \\
\hline Work role ambiguity & & & & & & & .02 & .06 & .02 \\
\hline Schedule control & & & & & & & -.64 & .12 & $-.24^{* *}$ \\
\hline$R^{2}$ & & .04 & & & .09 & & & .21 & \\
\hline Adjusted $R^{2}$ & & .01 & & & .08 & & & .19 & \\
\hline$F$ for change in $R^{2}$ & & .57 & & & $7.44^{* *}$ & & & $20.13^{* *}$ & \\
\hline
\end{tabular}

Gender: 0-female, 1-male; Marital Status: 0-single, 1-married; Spousal employment: 0-unemployed, 1-employed; ${ }^{*} \mathrm{p}<.05,{ }^{* *} \mathrm{p}<.001$.

\section{Results of Regression Analyses for Behavior-based WFC}

The results of the regression analyses for behavior-based WFC are shown in Table 4. As seen, no individual factors were significant in the first step. Family domain variables accounted for $10 \%$ of the variance in behavior-based WFC, with family role overload being the only significant predictor ( $\beta=$ $.32, p<.001)$. Finally, as predicted, work domain variables accounted for an additional $6 \%$ of variance in behavior-based WFC after controlling for the individual and family domain variables. In this final step, there were only two significant work domain, one individual domain, and two family domain predictors; schedule control was the strongest predictor $(\beta=-.21, p<.001)$ followed by work role overload $(\beta=.18, p<.05)$, age of the youngest child $(\beta=-.17, p<.05)$, gender $(\beta=.14, p<.05)$, and family role overload $(\beta=.14, \beta<.05)$.

Table 4. Summary of Hierarchical Regression Analysis for Variables Predicting Behavior-based WFC

\begin{tabular}{|c|c|c|c|c|c|c|c|c|c|}
\hline \multirow[b]{2}{*}{ Variable } & \multicolumn{3}{|c|}{ Model 1} & \multicolumn{3}{|c|}{ Model 2} & \multicolumn{3}{|c|}{ Model 3} \\
\hline & $B$ & $S E B$ & $\beta$ & $B$ & SE B & $\beta$ & $B$ & $S E B$ & $\beta$ \\
\hline Gender & .42 & .32 & .07 & .86 & .34 & $.17^{*}$ & .88 & .34 & $.14^{*}$ \\
\hline Age & -.05 & .02 & -.11 & .02 & .04 & .05 & .03 & .04 & .06 \\
\hline Tenure & -.01 & .02 & -.02 & -.01 & .02 & -.01 & -.01 & .02 & -.02 \\
\hline Family role overload & & & & .19 & .03 & $.32^{* *}$ & .09 & .04 & $.14^{*}$ \\
\hline Family role ambiguity & & & & .04 & .06 & .04 & .04 & .07 & .03 \\
\hline Marital status & & & & .81 & .91 & .02 & .71 & .93 & .02 \\
\hline Spousal employment & & & & .29 & .36 & .04 & .15 & .35 & .02 \\
\hline Number of children & & & & .12 & .21 & .03 & .19 & .21 & .05 \\
\hline Age of young child & & & & -.08 & .04 & -.16 & -.09 & .04 & $-.17^{*}$ \\
\hline Work role overload & & & & & & & .11 & .04 & $.18^{*}$ \\
\hline Work role ambiguity & & & & & & & -.01 & .06 & -.01 \\
\hline Schedule control & & & & & & & -.59 & .14 & $-.21^{* * *}$ \\
\hline$R^{2}$ & & .02 & & & .12 & & & .18 & \\
\hline Adjusted $R^{2}$ & & .01 & & & .10 & & & .15 & \\
\hline$F$ for change in $R^{2}$ & & 2.33 & & & $8.51^{* *}$ & & & $9.27^{* *}$ & \\
\hline
\end{tabular}

Gender: 0-female, 1-male; Marital Status: 0-single, 1-married; Spousal employment: 0-unemployed, 1-employed; ${ }^{*} \mathrm{p}<.05,{ }^{* *} \mathrm{p}<.001$. 


\section{Results of Regression Analyses for Time-based FWC}

The results of the regression analyses for time-based FWC are shown in Table 5. As seen, women reported more time-based FWC than men $(\beta=-.15, p<.01)$ and the younger the participants were, the more time-based conflict they experienced $(\beta=-.18, p<.01)$ in the first step. Work domain variables accounted for $18 \%$ of the variance in time-based FWC, with work role overload and schedule control being the only significant predictors $(\beta=.38, p<.001, \beta=-.13, p<.01)$. Finally, as predicted, family domain variables accounted for an additional $4 \%$ of variance in time-based FWC after controlling for the individual and work domain variables. In this final step, there were only two significant family domain and two work domain predictors; family role overload was the strongest predictor $(\beta=.23, p<.001)$ followed by work role overload $(\beta=.21, p<.05)$, age of the youngest child $(\beta=$ $-.18, p<.05)$, and schedule control $(\beta=-.11, p<.05)$.

Table 5. Summary of Hierarchical Regression Analysis for Variables Predicting Time-based FWC

\begin{tabular}{|c|c|c|c|c|c|c|c|c|c|}
\hline \multirow[b]{2}{*}{ Variable } & \multicolumn{3}{|c|}{ Model 1} & \multicolumn{3}{|c|}{ Model 2} & \multicolumn{3}{|c|}{ Model 3} \\
\hline & $B$ & $S E B$ & $\beta$ & $B$ & $S E B$ & $\beta$ & $B$ & $S E B$ & $\beta$ \\
\hline Gender & -.95 & .31 & $-.15^{* *}$ & -.65 & .28 & $-.10^{*}$ & -.17 & .32 & -.03 \\
\hline Age & -.08 & .02 & $-.18^{* *}$ & -.06 & .02 & $-.13^{*}$ & .00 & .04 & .01 \\
\hline Tenure & .01 & .02 & .01 & -.00 & .02 & -.01 & .00 & .02 & .01 \\
\hline Work role overload & & & & .23 & .03 & $.38^{* * *}$ & .13 & .04 & $.21^{* * *}$ \\
\hline Work role ambiguity & & & & -.07 & .05 & -.07 & -.04 & .06 & -.04 \\
\hline Schedule control & & & & -.36 & .13 & $-.13^{* *}$ & -.31 & .13 & $-.11^{*}$ \\
\hline Family role overload & & & & & & & .13 & .04 & $.23^{* * *}$ \\
\hline Family role ambiguity & & & & & & & -.04 & .06 & -.03 \\
\hline Marital status & & & & & & & -.58 & .97 & -.04 \\
\hline Spousal employment & & & & & & & .59 & .32 & .08 \\
\hline Number of children & & & & & & & .12 & .19 & .03 \\
\hline Age of young child & & & & & & & -.09 & .04 & $-.18^{*}$ \\
\hline$R^{2}$ & & .06 & & & .24 & & & .28 & \\
\hline Adjusted $R^{2}$ & & .05 & & & .23 & & & .26 & \\
\hline$F$ for change in $R^{2}$ & & $9.58^{*}$ & & & $33.63^{* *}$ & & & $3.92^{*}$ & \\
\hline
\end{tabular}

Gender: 0-female, 1-male; Marital Status: 0-single, 1-married; Spousal employment: 0-unemployed,

1-employed; ${ }^{*} \mathrm{p}<.05,{ }^{* *} \mathrm{p}<.001,{ }^{* * *} \mathrm{p}<.001$.

\section{Results of Regression Analyses for Strain-based FWC}

The results of the regression analyses for strain-based FWC are shown in Table 6. As seen, the younger participants reported more strain-based conflict $(\beta=-.19, p<.01)$ in the first step. Work domain variables accounted for $10 \%$ of the variance in strain-based FWC, with schedule control and work role overload being the only significant predictors $(\beta=-.21, p<.001, \beta=-.19, p<.001)$. Finally, as predicted, family domain variables accounted for an additional $4 \%$ of variance in strain-based FWC after controlling for the individual and work domain variables. In this final step, there were only two significant family domain, one individual domain, and one work domain predictors; family role overload was the strongest predictor $(\beta=.24, p<.001)$ followed by schedule control $(\beta=-.19, p<.01)$, age of the youngest child $(\beta=-.17, p<.05)$, and gender $(\beta=.15, p<.01)$. 
Table 6. Summary of Hierarchical Regression Analysis for Variables Predicting Strain-based FWC

\begin{tabular}{|c|c|c|c|c|c|c|c|c|c|}
\hline \multirow[b]{2}{*}{ Variable } & \multicolumn{3}{|c|}{ Model 1} & \multicolumn{3}{|c|}{ Model 2} & \multicolumn{3}{|c|}{ Model 3} \\
\hline & $B$ & $S E B$ & $\beta$ & $B$ & $S E B$ & $\beta$ & $B$ & $S E B$ & $\beta$ \\
\hline Gender & .31 & .33 & .05 & .55 & .31 & .08 & .92 & .36 & $.15^{* *}$ \\
\hline Age & -.08 & .02 & $-.19^{* *}$ & -.06 & .02 & $-.14^{* *}$ & .01 & .04 & .02 \\
\hline Tenure & .00 & .03 & .00 & -.01 & .02 & -.01 & .00 & .02 & .00 \\
\hline Work role overload & & & & .12 & .03 & $.19^{* * *}$ & .01 & .04 & .02 \\
\hline Work role ambiguity & & & & -.03 & .05 & -.03 & -.06 & .07 & -.05 \\
\hline Schedule control & & & & -.63 & .14 & $-.21^{* * *}$ & -.58 & .14 & $-.19^{* * *}$ \\
\hline Family role overload & & & & & & & .16 & .04 & $.24^{* * *}$ \\
\hline Family role ambiguity & & & & & & & .08 & .07 & .06 \\
\hline Marital status & & & & & & & -.95 & .67 & -.04 \\
\hline Spousal employment & & & & & & & .25 & .36 & .03 \\
\hline Number of children & & & & & & & -.21 & .21 & -.05 \\
\hline Age of young child & & & & & & & -.09 & .04 & $-.17^{*}$ \\
\hline$R^{2}$ & & .03 & & & .13 & & & .17 & \\
\hline Adjusted $R^{2}$ & & .03 & & & .12 & & & .15 & \\
\hline$F$ for change in $R^{2}$ & & $4.97^{* *}$ & & & $16.23^{* * *}$ & & & $3.39^{* *}$ & \\
\hline
\end{tabular}

Gender: 0-female, 1-male; Marital Status: 0-single, 1-married; Spousal employment: 0-unemployed,

1-employed; ${ }^{*}<.05,{ }^{* *} \mathrm{p}<.001,{ }^{* * *} \mathrm{p}<.001$.

\section{Results of Regression Analyses for Behavior-based FWC}

The results of the regression analyses for behavior-based FWC are shown in Table 7. As seen, no individual factors were significant in the first step. Work domain variables accounted for $12 \%$ of the variance in behavior-based FWC, with work role overload and schedule control being the only significant predictors $(\beta=.24, p<.001, \beta=-.22, p<.001)$. Finally, contrary to expectations, family domain variables did not account a significant variance in behavior-based FWC after controlling for the individual and work domain variables. In this final step, there were only one significant family domain and two work domain predictors; schedule control was the strongest predictor $(\beta=-.22, p<$ $.001)$ followed by age of the youngest child $(\beta=-.18, p<.05)$, and work role overload $(\beta=.17, p<.05)$.

Table 7. Summary of Hierarchical Regression Analysis for Variables Predicting Behavior-based FWC

Variable

Gender

Age

Tenure

Work role overload

Work role ambiguity

Schedule control

Family role overload

Family role ambiguity

Marital status

Spousal employment

Number of children

Age of young child

$R^{2}$

Adjusted $R^{2}$

$F$ for change in $R^{2}$

\begin{tabular}{ccc}
\multicolumn{3}{c}{ Model 1 } \\
\hline$B$ & $S E B$ & $\beta$ \\
.32 & .33 & .05 \\
-.02 & .03 & -.05 \\
.01 & .03 & .01
\end{tabular}

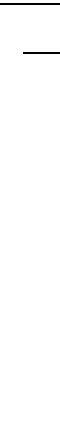

\begin{tabular}{ccccccc}
\multicolumn{3}{c}{ Model 2 } & & \multicolumn{3}{c}{ Model 3 } \\
\cline { 6 - 7 }$B$ & SE B & $\beta$ & & $B$ & SE B & $\beta$ \\
.59 & .31 & .09 & & .71 & .36 & .11 \\
.00 & .02 & .00 & & .06 & .04 & .14 \\
-.01 & .02 & -.01 & & .00 & .02 & .00 \\
.15 & .03 & $.24^{* * *}$ & & .11 & .04 & $.17^{*}$ \\
.01 & .05 & .01 & & .05 & .07 & .04 \\
-.66 & .14 & $-.22^{* * *}$ & & -.65 & .15 & $-.22^{* * *}$ \\
& & & & .06 & .04 & .09 \\
& & & -.08 & .07 & -.07 \\
& & & & .17 & .65 & .01 \\
& & & .08 & .37 & .01 \\
& & & & .14 & .22 & .04 \\
& & & & -.09 & .04 & $-.18^{*}$ \\
& .13 & & & .15 & \\
& .12 & & & .13 & \\
$21.09^{* *}$ & & & & 1.57 & \\
\hline
\end{tabular}

Gender: 0-female, 1-male; Marital Status: 0-single, 1-married; Spousal employment: 0-unemployed, 1-employed; ${ }^{*}<<.05,{ }^{* *} \mathrm{p}<.001,{ }^{* * *} \mathrm{p}<.001$. 


\section{Discussion}

This study sought to expand the literature on the potential antecedents of multidimensional work-family conflict within higher education settings where work overload, unscheduled work load, long working hours, diversity of teaching and research roles are in common. Drawing on previous research and theory, two hypotheses were formulated to assess the relative contributions of work domain and family domain antecedents on three forms of WFC and FWC.

As hypothesized (Hypothesis 1), work domain variables accounted for significant variance in three forms of WFC (time-based, strain-based, and behavior-based) after controlling for the individual and family domain variables. These findings empirically support the claim that work related factors are expected to be more associated to WFC than to FWC (Byron, 2005). Two meta-analytic work on antecedents of WFC and FWC are also in line with these findings (Byron, 2005; Michel et al., 2011). In Byron's (2005) meta-analytic work combined from more than 60 studies, all work domain variables (e.g., job involvement, hours spent at work, work support, schedule flexibility, job stress, work role overload) had a greater impact on WFC than on FWC in the expected direction. A further metaanalytic study by Michel et al. (2011) which searched for 142 studies, work domain variables (e.g., job stressors, work role conflict, work role overload, organizational support) had larger effect sizes for WFC when compared with FWC. For example, effect size for job stress predicting WFC was .50 whereas it was .24 when predicting FWC in Cohen's (1992) classification of correlation magnitudes. Similar results were found for work role conflict $(\mathrm{WFC}=.41, \mathrm{FWC}=.25)$, work role overload (WFC = $.55, \mathrm{FWC}=.26)$, organizational support $(\mathrm{WFC}=-.30, \mathrm{FWC}=-.14)$, supervisor support $(\mathrm{WFC}=-.22$, FWC $=-.11)$, and coworker support $(\mathrm{WFC}=-.25, \mathrm{FWC}=-.14)$.

In analyzing the relative contributions of work domain antecedents on the three dimensions of WFC, two emerging work domain antecedents were work role overload and schedule control. That is, academic staffs' time-based, strain-based, and behavior-based WFC tended to decrease when they feel less work role overload and more control on their working schedule. This finding is in line with the findings of Byron (2005) that role overload and schedule flexibility were most strongly correlated with WFC. Michel et al.'s (2011) study also supports this finding that work role overload had large relationship with WFC. In addition to these various sectoral studies, findings from university employees consistently demonstrate that work role overload is an important factor adding to work family conflict of male and female faculty (Doherty \& Manfredi, 2006; Jacobs \& Winslow, 2004; Pillay et al., 2013).

Hypothesis 2 was partially supported that family domain variables accounted for significant variance in two forms of FWC (time-based and strain-based) after controlling for the individual and work domain variables except for behavior-based FWC. One possible explanation is that work factors were still effective in FWC dimensions suggesting that work factors have priority to family factors in predicting behavior-based FWC or they can be equally important to WFC and FWC (Hargis, Kotrba, Zhdanova, \& Baltes, 2011). Another explanation may be that there are other factors influencing behavior-based FWC than family domain variables included within the current study. For instance, a study examining relative importance of antecedents to WFC and FWC (Hargis et al., 2011) has revealed that negative affectivity was the strongest predictor of behavior-based FWC and fully dominated the remaining family domain antecedents whereas none of the family factors (e.g., family stress, number of children, age of the youngest child, family involvement, and family support) were significant predictors.

Two emerging family domain antecedents were family role overload and age of the youngest child. That is, academic staff reported less FWC if they feel less family role overload and have older aged children. These findings were also consistent with the Byron's (2005) meta-analytic study, suggesting that family stress measured by stress stem from family role overload, conflict, or ambiguity, family conflict, and age of the youngest child are most strongly related factors to WFC. In Michel et al.'s study (2011), however, age of the youngest child was not a significant predictor whereas 
family role overload had moderate relationship with FWC. Michel et al. (2011) explains this discrepancy with the operationalization of the constructs and different measures used for assessment of work family conflict. A qualitative study (Beddoes \& Pawley, 2014) conducted with 19 STEM (Science, Technology, Engineering, and Mathematics) faculty members also supports the current findings that the most common factors making family work balance worse are family-related responsibilities, including childcare and housework.

Limitations in this study include the cross-sectional nature of the study design which does not permit to draw detailed causal conclusions between the antecedents and work family conflict, thus longitudinal research is required for detailed conclusions. Another limitation is about the assessment of role overload, role ambiguity, and schedule control with single, two, or three item indexes. Future studies may use more in-depth measures for these constructs. A third limitation is about the selection of possible antecedents because it is not possible to include all individual, work, and family domain antecedents in a single study. Thus, further studies should examine other potential work, family, and individual antecedents of W-F and F-W conflict among academic staff which was not included within this study such as, social support provided from work environment and family, coping skills, personality traits. Replications of these antecedents are also important for the generalizability of the potential antecedents of time-based, strain-based, and behavior-based WFC and FWC among academic staff to further use these information to develop new policies and interventions at universities. A last implication for future research may be to test the moderation effects of gender between the potential antecedents and WFC. Findings of the current study revealed that male faculty reported more time-based and behavior-based WFC whereas female faculty time-based FWC. While there are inconsistent results concerning gender differences for WFC and FWC (Parasuraman \& Greenhaus, 2002; Pillay et al., 2013), potential gender effects within academic staff in Turkey should further be examined.

Results of this study have also implications for practice. A clear understanding of specific antecedents for specific populations is critical for organizations and their policies to reduce WFC which have many harmful aforementioned effects. When designing interventions targeting to decrease WFC, the importance of work role overload and schedule control should be taken into consideration. For instance, academic staff would participate in activities of time-management under the leadership of a specialist to increase their time-management skills and to decrease work to family conflict. Similarly, when designing interventions targeting to decrease FWC, the importance of family role overload and age of the youngest child should be taken into consideration. For instance, academic staff would participate in activities as a couple and work on role balance issues under the leadership of a specialist to decrease family to work conflict. Besides, childcare services provided by the universities for academic staff who are parents of young children should be improved.

Currently, there are theory-based, structured, and empirically tested intervention programs to decrease W-F and F-W conflict (Cinamon \& Rich, 2005; Haslam, Sanders, \& Sofronoff, 2013). They include: (a) raising manager awareness of the causes and consequences of WFC, (b) enhancing manager understanding of family-friendly organizational policy, (c) boosting at-risk employee understanding of work and family role identities, (d) improving at-risk employees' skills and attitudes enabling successful blending of roles, (e) increasing at-risk employees' self-efficacy for management of WFC, (f) teaching a range of parenting strategies, and (g) teaching stress inoculation strategies such as working with unhelpful thoughts, progressive muscle relaxation, and diaphragmatic breathing. These programs for managers, employees, or teachers should be adapted to specifically for academic staff in Turkey. The results of the current study on the potential antecedents of work family conflict would add to the development of these kind of programs. 


\section{References}

Allen, T. D., Herst, D. E. L., Bruck, C. S., \& Sutton, M. (2000). Consequences associated with work-tofamily conflict: A review and agenda for future research. Journal of Occupational Health Psychology, 5, 278-308.

Amstad, F. T., Meier, L. L., Fasel, U., Elfering, A., \& Semmer, N. K. (2011). A meta-analysis of workfamily conflict and various outcomes with a special emphasis on cross-domain versus matchingdomain relations. Journal of Occupational Health Psychology, 16, 151-169.

Anderson, S. E., Coffey, B. S., \& Byerly, R. T. (2002). Formal organizational initiatives and informal workplace practices: Links to work-family conflict and job-related outcomes. Journal of management, 28, 787-810.

Anderson, D. M., Morgan, B. L., \& Wilson, J. B. (2002). Perceptions of family-friendly policies: University versus corporate employees. Journal of Family and Economic Issues, 23, 73-92.

Beddoes, K., \& Pawley, A. L. (2014). 'Different people have different priorities': Work-family balance, gender, and the discourse of choice. Studies in Higher Education, 39, 1573-1585.

Boles, J. S., Howard, W. G., \& Donofrio, H. H. (2001). An investigation into the inter-relationships of work-family conflict, family-work conflict and work satisfaction. Journal of Managerial Issues, 13, 376-390.

Britt, T. W., \& Dawson, C. R. (2005). Predicting work-family conflict from workload, job attitudes, group attributes, and health: A longitudinal study. Military Psychology, 17, 203-227.

Browne, M. W., \& Cudeck, R. (1993). Alternative ways of assessing model fit. In K. A. Bollen, \& J. S. Long (Eds.), Testing structural equation models (pp. 136-162). Newbury Park, CA: Sage.

Burke, R. J., \& Greenglass, E. R. (2001). Hospital restructuring, work-family conflict and psychological burnout among nursing staff. Psychology \& Health, 16, 583-594.

Byron, K. (2005). A meta-analytic review of work-family conflict and its antecedents. Journal of Vocational Behavior, 67, 169-198.

Carlson, D. S., Kacmar, K. M., \& Williams, L. J. (2000). Construction and initial validation of a multidimensional measure of work-family conflict. Journal of Vocational Behavior, 56(2), 249-276.

Cinamon, R. G., \& Rich, Y. (2002). Profiles of attribution of importance to life roles and their implications for the work-family conflict. Journal of Counseling Psychology, 49, 212-220.

Cohen, J. (1992). A power primer. Psychological Bulletin, 112, 155-159.

Cohen, A., \& Kirchmeyer, C. (1995). A multidimensional approach to the relation between organizational commitment and nonwork participation. Journal of Vocational Behavior, 46, 189-202.

Currie, J., Harris, P., \& Thiele, B. (2000). Sacrifices in greedy universities: Are they gendered? Gender and Education, 12, 269-291.

Darcy, C., \& McCarthy, A. (2007). Work-family conflict: An exploration of the differential effects of a dependent child's age on working parents. Journal of European Industrial Training, 31, 530-549.

Doherty, L., \& Manfredi, S. (2006). Action research to develop work-life balance in a UK university. Women in Management Review, 21, 241-259.

Edwards, J. R., \& Rothbard, N. P. (2000). Mechanisms linking work and family: Clarifying the relationship between work and family constructs. Academy of Management Review, 25, 178-199.

Fox, M. L., \& Dwyer, D. J. (1999). An investigation of the effects of time and involvement in the relationship between stressors and work-family conflict. Journal of Occupational Health Psychology, 4, 164-174.

Frone, M. R. (2000). Work-family conflict and employee psychiatric disorders: The national comorbidity survey. Journal of Applied Psychology, 85, 888-895. 
Frone, M. R., Russell, M., \& Cooper, M. L. (1992). Antecedents and outcomes of work-family conflict: Testing a model of the work-family interface. Journal of Applied Psychology, 77, 65-78.

Greenhaus, J. H., \& Beutell, N. J. (1985). Sources of conflict between work and family roles. Academy of Management Review, 10, 76-88.

Greenhaus, J. H., Parasuraman, S., \& Collins, K. M. (2001). Career involvement and family involvement as moderators of relationships between work-family conflict and withdrawal from a profession. Journal of Occupational Health Psychology, 6, 91-100.

Hammer, L. B., Cullen, J. C., Neal, M. B., Sinclair, R. R., \& Shafiro, M. V. (2005). The longitudinal effects of work-family conflict and positive spillover on depressive symptoms among dualearner couples. Journal of Occupational Health Psychology, 10, 138-154.

Hargis, M. B., Kotrba, L. M., Zhdanova, L., \& Baltes, B. B. (2011). What's really important? Examining the relative importance of antecedents to work-family conflict. Journal of Managerial Issues, 23, 386408.

Haslam, D. M., Sanders, M. R., \& Sofronoff, K. (2013). Reducing work and family conflict in teachers: A randomised controlled trial of Workplace Triple P. School Mental Health, 5, 70-82.

Hu, L., \& Bentler, P. M. (1999). Cutoff criteria for fit indices in covariance structure analysis: Conventional versus new alternatives. Structural Equation Modeling, 6, 1-55.

Jacobs, J. A., \& Winslow, S. E. (2004). Overworked faculty: Job stresses and family demands. The Annals of the American Academy of Political and Social Science, 596, 104-129.

Kahn, R. L., Wolfe, D. M., Quinn, R. P., Snoek, J. D., \& Rosenthal, R. A. (1964). Organizational stress. NewYork: Wiley.

Kinnunen, U., Feldt, T., Mauno, S., \& Rantanen, J. (2010). Interface between work and family: A longitudinal individual and crossover perspective. Journal of Occupational and Organizational Psychology, 83, 119-137.

Kirchmeyer, C., \& Cohen, A. (1999). Different strategies for managing the work non-work interface: A test for unique pathways to work outcomes. Work and Stress, 13, 59-73.

Matthews, R. A., Kath, L. M., \& Barnes-Farrell, J. L. (2010). A short, valid, predictive measure of workfamily conflict: Item selection and scale validation. Journal of occupational health psychology, 15, 7590.

Michel, J. S., Kotrba, L. M., Mitchelson, J. K., Clark, M. A., \& Baltes, B. B. (2011). Antecedents of workfamily conflict: A meta-analytic review. Journal of Organizational Behavior, 32, 689-725.

Morris, M. L., \& Madsen, S. R. (2007). Advancing work-life integration in individuals, organizations, and communities. Advances in Developing Human Resources, 9, 439-454.

Netemeyer, R. G., Boles, J. S., \& McMurrian, R. (1996). Development and validation of work-family conflict and family-work conflict scales. Journal of Applied Psychology, 81, 400-410.

Nohe, C., \& Sonntag, K. (2014). Work-family conflict, social support, and turnover intentions: A longitudinal study. Journal of Vocational Behavior, 85, 1-12.

Parasuraman, S., \& Greenhaus, J. H. (2002). Toward reducing some critical gaps in work-family research. Human Resource Management Review, 12, 299-312.

Perrewe, P. L., Hochwarter, W. A., \& Kiewitz, C. (1999). Value attainment: An explanation for the negative effects of work-family conflict on job and life satisfaction. Journal of Occupational Health Psychology, 4, 318-326.

Pillay, S., \& Abhayawansa, S. (2014). Work-family balance: Perspectives from higher education. Higher Education, 68, 669-690.

Pillay, S., Kluvers, R., Abhayawansa, S., \& Vranic, V. (2013). An exploratory study into work/family balance within the Australian higher education sector. Higher Education Research \& Development, $32,228-243$. 
Rantanen, J., Kinnunen, U., Feldt, T., \& Pulkkinen, L. (2008). Work-family conflict and psychological well-being: Stability and cross-lagged relations within one- and six-year follow-ups. Journal of Vocational Behavior, 73, 37-51.

Reichl, C., Leiter, M. P., \& Spinath, F. M. (2014). Work-nonwork conflict and burnout: A meta-analysis. Human Relations, 67, 979-1005.

Schuler, R. S., Aldag, R. J., \& Brief, A. P. (1977). Role conflict and ambiguity: A scale analysis. Organizational Behavior and Human Performance, 20(1), 111-128.

Staines, G. L., \& O'Connor, P. (1980). Conflicts among work, leisure, and family roles. Monthly Labor Review, 103, 35-39.

Stewart, L. M. (2013). Family care responsibilities and employment: Exploring the impact of type of family care on work-family and family-work conflict. Journal of Family Issues, 34, 113-138.

Stoeva, A. Z., Chiu, R. K., \& Greenhaus, J. H. (2002). Negative affectivity, role stress, and work-family conflict. Journal of Vocational Behavior, 60, 1-16.

Symoens, S., \& Bracke, P. (2015). Work-family conflict and mental health in newlywed and recently cohabiting couples: A couple perspective. Health Sociology Review, 24, 48-63.

Tabachnick, B. G., \& Fidell, L. S. (2001). Using multivariate statistics (4th ed.). Needham Heights, MA: Allyn \& Bacon.

Thiagarajan, P., Chakrabarty, S., \& Taylor, R. D. (2006). A confirmatory factor analysis of Reilly's Role Overload Scale. Educational and Psychological Measurement, 66, 657-666. 